\title{
Pölyille ja ammoniakille altistuminen turvepohjasikaloissa
}

\author{
Jukka Mäittälä, Sirpa Rautiala ja Juhani Kangas \\ Työterveyslaitos, PL 9370701 Kuopio, jukka.maittala@occuphealth.fi
}

\section{Johdanto}

Sikaloissa työskentelevillä on tavanomaista enemmän hengitystieoireita (Donham et al. 1989, Crook et al. 1991). Sikalapölyn on todettu aiheuttavan altistuneiden henkilöiden hengitysteissä ärsytysvaikutuksia sekä allergisia sairauksia. Sikalailmassa on eläimistä, rehuista ja kuivikkeista peräisin olevaa epäorgaanista ja orgaanista pölyä, jossa voi olla mikrobeja ja niiden toksisia rakenneosia (endotoksiini). Tämän lisäksi sikalailmassa esiintyy ärsyttäviä kaasuja mm. ammoniakkia.

Kuopion aluetyöterveyslaitos, Jyväskylän yliopisto ja MTT toteuttivat vuosina 1995-97 tutkimuksen, jossa selvitettiin, kuinka paljon purupohjasikalassa muodostuu haitallisia kemiallisia ja mikrobiologisia epäpuhtauksia ja arvioitiin niiden vaikutuksia hajupäästöihin ja sikalan työntekijöiden terveyteen. Tutkimuksessa todettiin, että hyvin toimivassa purupohjasikalassa ammoniakki- ja rikkiyhdistepitoisuudet olivat pienempiä kuin vastaavissa perinteisissä sikaloissa. Samoin pienenivät sikalan hajupäästöt. Sen sijaan purupohjasikalassa ilman mikrobipitoisuudet olivat suurempia kuin perinteisissä sikaloissa. Sekä perinteisessä että purupohjasikalassa endotoksiinipitoisuudet olivat samaa tasoa.

Ongelmana useissa purupohjasikaloissa oli pohjan huono kompostoituminen. Syynä tähän oli liian suuri sikamäärä pinta-alayksikköä kohti sekä talviaikaan lisälämmön puute ja huono ilmanvaihto, jolloin purupohja kostui liikaa ja kompostoitumisprosessi hiipui (Louhelainen et al. 1998). Koska pohjan liiallinen kosteus on merkittävä syy kompostoitumisen hiipumiseen, tässä tutkimuksessa kokeiltiin turpeen ja oljen seosta kompostisikalan pohjan materiaalina. Olettamuksena oli, että hyvän imukykynsä ansiosta turve voisi tarjota ainakin osittaisen ratkaisun purupohjassa esiintyneeseen kuivikkeen kostumisongelmaan. Lisäksi käyttämällä kuivikeseoksessa turvetta oletettiin kuivikepohjasta vapautuvan ammoniakin määrän vähentyvän ratkaisevasti. Aiemmissa selvityksissä on osoitettu, että turve absorboi ammoniakkia ja rikkivetyä tehokkaasti (Manninen et al. 1989).

Tämä tutkimus on osa laajempaa hanketta, jossa selvitettiin turve-olkipohjaisen kompostisikalan vaikutuksia ympäristöön, ympäristön viihtyisyyteen ja viljelijöiden terveyteen (Mäittälä et al. 2001). Tässä tutkimuksessa selvitettiin turvepohjan käyttäytymistä ja ominaisuuksia työntekijän altistumisen kannalta. Tätä varten ilmasta kerättiin erilaisia pöly- ja kaasunäytteitä.

\section{Aineisto ja menetelmät}

Tutkimukseen osallistui viisi sikalaa Keski-Suomesta. Sikaloista kolme toimi jatkuvatäytteisenä kasvatussikalana, yksi kertatäyttöisenä kasvatussikalana ja yksi yhdistelmäsikalana. Sikalat olivat kokeen alkuvaiheessa purupohjalla, mutta vaihtoivat ensimmäisten mittausten jälkeen purun turveolkiseokseen. Turvepohjan aikana tiloilla tehtiin erilaisia mittauksia talvella ja kesällä kolmesta viiteen kertaan tilaa kohti.

Hengittyvä pöly kuvaa työntekijän hengitysteihin pääsevää osuutta sikalan ilmassa leijuvasta orgaanisen ja epäorgaanisen pölyn kokonaismäärästä. Sikaloiden ilman hengittyvän pölyn pitoisuudet määritettiin turvepohjalla taustatilanteessa kahdesta kiinteästä mittauspisteestä sikalan käytävillä. Taustanäytteiden lisäksi työvaiheiden aikana kerättiin pölynäytteet työntekijän hengitysvyöhykkeeltä. Tutkitut työvaiheet olivat sikojen siirto karsinoista, sikojen siirtely karsinoista toisiin ja pohjan kääntö sekä pohjan osittainen uudistaminen märän massan poisviennillä ja uuden turpeen levityksellä. Pölynäytteet kerättiin näytteenottopumpulla IOM-keräimen selluloosa-asetaattisuodattimelle. Näytteiden pölypitoisuudet määritettiin gravimetrisesti. Tulokset ilmoitetaan yksikössä mg/m³

Sikaloiden ilmasta määritettiin elinkykyisten mikrobien pitoisuudet 6-vaiheisella Andersenimpaktorilla keräämällä ne kasvatusalustoille. Näytteistä määritettiin mesofiilisten eli huoneen lämmössä viihtyvien, kserofiilisten eli kuivemmissa oloissa viihtyvien ja termotoleranttien eli lämpösietoisten sieni-itiöiden, gram-negatiivisten bakteerien ja termofiilisten eli lämpöhakuisten aktinobakteerien pitoisuudet. Mikrobipesäkkeet tunnistettiin kasvatuksen jälkeen mikroskopoimalla laji/sukutasolle. Tulokset ilmoitetaan yksikössä $\mathrm{cfu} / \mathrm{m}^{3}(\mathrm{cfu}=$ colony forming unit $=$ pesäkkeen muodostava yksikkö). 
Kokonaisitiöpitoisuuden määrityksiä varten sikaloista kerättiin ilmanäytteitä kalvosuodattimelle näytteenottopumpulla. Näytteenoton jälkeen suodattimilta määritettiin kokonaisitiöpitoisuudet akridiinioranssivärjäykseen perustuvalla Camnea-menetelmällä. Tulokset ilmoitetaan yksikössä $\mathrm{kpl} / \mathrm{m}^{3}$.

Endotoksiininäytteet kerättiin IOM-keräimessä oleville lasikuitusuodattimille. Näytteistä määritettiin endotoksiinipitoisuudet Limulus Amebosyytti Lysaatti-entsyymiin perustuvalla spektrofotometrisellä menetelmällä. Tulokset ilmoitetaan yksikössä $\mathrm{ng} / \mathrm{m}^{3}$.

Sikalailman ammoniakkipitoisuus määritettiin suoraanosoittavalla diffuusioputkella. Putket asetettiin kahteen kiinteään mittauspisteeseen taustatilanteessa ja työvaiheiden aikana. Näytteenottoaika oli tunti, jonka jälkeen pitoisuus $\left(\mathrm{cm}^{3} / \mathrm{m}^{3}\right.$ eli miljoonasosaa (ppm)) luettiin välittömästi putken pitoisuusasteikolta.

\section{Tulokset ja tulosten tarkastelu}

Kaikissa sikaloissa oli turvepölyä kertynyt tasopinnoille ja käytäville. Turvesikaloiden sisäilmasta mitatut hengittyvän pölyn pitoisuudet olivat taustatilanteessa keskimäärin $4,0 \mathrm{mg} / \mathrm{m}^{3}$, mutta pitoisuudet vaihtelivat erittäin paljon (taulukko 1). Työvaiheen aikaiset kiinteistä mittauspisteistä mitatut pitoisuudet olivat keskimäärin $7,5 \mathrm{mg} / \mathrm{m}^{3}$. Samojen työvaiheiden aikaisissa hengitysvyöhykenäytteissä hengittyvän pölyn pitoisuus oli keskimäärin $10 \mathrm{mg} / \mathrm{m}^{3}$. Nämä pitoisuudet ovat selvästi suurempia kuin purupohjasikaloissa mitatut pitoisuudet taustatilanteessa tai työvaiheen aikana (Louhelainen et al. 1998). Orgaanisen pölyn haitalliseksi tunnettu pitoisuus (HTP) on kahdeksan tunnin altistumisajalle $5 \mathrm{mg} / \mathrm{m}^{3}$. Työvaiheiden aikaiset keskimääräiset pitoisuudet ylittivät tuon ohjearvon selvästi. Työntekijöiden hengitysvyöhykkeeltä määritetyt hengittyvän pölyn pitoisuudet ylittivät aina työpäivän ohjearvon, ja usein myös lyhyen ajan altistumisen ohjearvon, 10 $\mathrm{mg} / \mathrm{m}^{3}$ (HTP $\left.15 \mathrm{~min}\right)$. Myös taustatilanteessa pitoisuudet olivat yli puolessa mittauksista kahdeksan tunnin ohjearvon yläpuolella.

Taulukko 1. Hengittyvän pölyn määrä turvepohjaisten kompostisikaloiden työilmassa taustatilanteessa, tietyn työvaiheen aikana sekä työntekijän hengitysvyöhykkeellä kyseisen työvaiheen aikana. GM = geometrinen keskiarvo, $\mathrm{AM}=$ aritmeettinen keskiarvo, $\mathrm{N}=$ mittausten lukumäärä.

\begin{tabular}{|l|l|l|l|l|}
\hline $\begin{array}{l}\text { Hengittyvä pöly, } \\
\text { mg/m }\end{array}$ & GM & AM & Vaihteluväli & N \\
\hline $\begin{array}{l}\text { Taustatilanne } \\
\text { (kiinteä mittauspiste) }\end{array}$ & 4,0 & 6,6 & $0,4-34,0$ & 37 \\
\hline $\begin{array}{l}\text { Työvaihe } \\
\text { (kiinteä mittauspiste) }\end{array}$ & 7,5 & 9,8 & $3,5-41,0$ & 15 \\
\hline $\begin{array}{l}\text { Työvaihe } \\
\text { (hengitysvyöhykenäyte) }\end{array}$ & 10,0 & 11,0 & $5,3-15,0$ & 5 \\
\hline
\end{tabular}

Ilman mikrobipitoisuudet olivat taustatilanteissa ja työvaiheiden aikana keskimäärin 10-100 kertaa korkeampia $\left(10^{5}-10^{7} \mathrm{kpl} / \mathrm{m}^{3}\right)$ kuin purupohjasikaloissa ja perinteisissä lietelantasikaloissa. Turvepohjasikaloiden ilmassa esiintyi runsaasti termotolerantteja sieni-itiöitä ja termofiilisiä aktinobakteereja, joita pidetään homepölykeuhkon aiheuttajina (kuva 1). Lisäksi turvepohjasikaloissa mikrobisuvusto oli monipuolisempi kuin purupohjasikaloissa. 


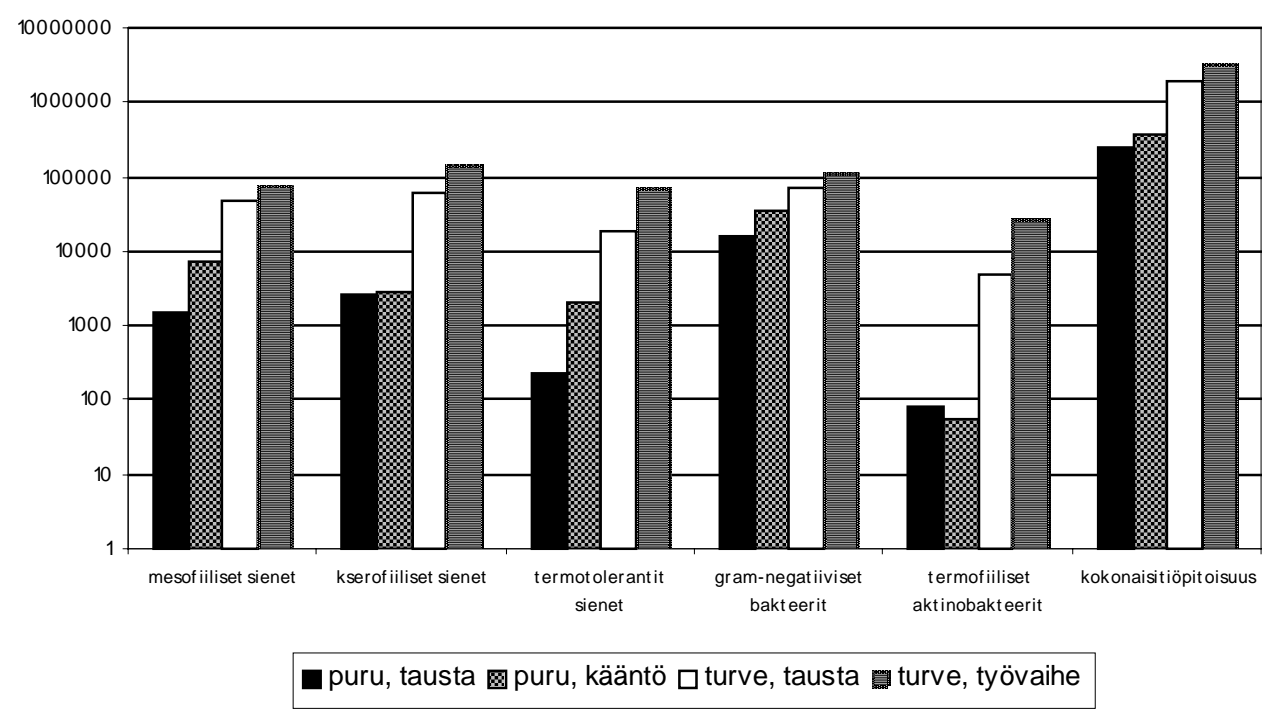

Kuva 1. Elinkykyisten sieni-itiöiden ja aktinobakteerien pitoisuuksien sekä kokonaisitiöpitoisuuksien geometriset keskiarvot puru- ja turvepohjasikaloissa. Elinkykyisten mikrobien pitoisuudet on esitetty yksikössä cfu/m $\mathrm{m}^{3} \mathrm{ja}$ kokonaisitiöpitoisuudet yksikössä $\mathrm{kpl} / \mathrm{m}^{3}$.

Turveolkisikaloista otetuissa näytteissä endotoksiinipitoisuudet olivat taustanäytteissä 170-4900 $\mathrm{ng} / \mathrm{m}^{3}$ ja työvaiheiden aikaiset pitoisuudet $320-3100 \mathrm{ng} / \mathrm{m}^{3}$. Pitoisuuksissa ei ollut juurikaan eroa purupohjasikaloiden näytteisiin verrattuna. Nämä pitoisuudet ovat pienempiä kuin perinteisissä lietelantasikaloissa mitatut pitoisuudet (Louhelainen et al. 1998). Suurimmaksi sallituksi työilman endotoksiinipitoisuudeksi on ehdotettu $20-30 \mathrm{ng} / \mathrm{m}^{3}$. Tässä tutkimuksessa nämä arvot ylittyivät selvästi.

Tutkittavista sikaloista purupohjan aikana mitatut taustatilanteen ammoniakkipitoisuudet olivat keskimäärin 24 ppm, ja pohjan käännön aikana keskimäärin 13 ppm. Turvepohjan aikana mitatut taustapitoisuudet olivat keskimäärin 9 ppm, ja työvaiheiden aikana 6 ppm (taulukko 2). Turvepohjalla ammoniakkipitoisuudet olivat noin puolet purupohjasikaloissa sekä perinteisissä lietelantasikaloissa mitatuista pitoisuuksista (Kangas et al. 1987 ja Louhelainen et al. 1998). Ammoniakin $\mathrm{HTP}_{8 \mathrm{~h}}$-arvo on $25 \mathrm{ppm}$ ja lyhytaikaisen altistumisen ohjearvo $40 \mathrm{ppm}$. Keskimäärin pitoisuudet jäivät alle ohjearvojen.

Taulukko 2. Kiinteistä mittauspisteistä mitatut ammoniakkipitoisuudet (ppm) tiloilla purupohjan aikana sekä turvepohjan aikana eri mittauskerroilla. Määritysraja on $1 \mathrm{ppm}$.

\begin{tabular}{|c|l|l|l|l|l|l|l|}
\hline $\mathbf{N H}_{3}, \mathbf{p p m}$ & Puru & Turve1 & Turve2 & Turve3 & Turve4 & Turve5 & Turve6 \\
\hline Tila 1 & 45 & 20 & 10 & & 2 & & 18 \\
\hline työvaihe & 15 & & 5 & & 2 & & \\
\hline Tila 2 & 15 & 30 & 20 & & $<1$ & $<1$ & \\
\hline työvaihe & 5 & & 10 & & & & \\
\hline Tila 3 & 20 & 20 & 2 & & 10 & 2 & \\
\hline työvaihe & 20 & & $<1$ & & & & \\
\hline Tila 4 & 15 & & 15 & & $<1$ & & \\
\hline työvaihe & & & 15 & & & & \\
\hline Tila 5 & & & & 1 & 3 & 10 & 7 \\
\hline
\end{tabular}




\section{Johtopäätökset}

Kuivan turpeen voimakasta pölyämistä sekä osin siitä johtuen korkeita ilman mikrobipitoisuuksia voidaan pitää tutkimuksen perusteella suurimpana ongelmana turvesikalan työolosuhteita ajatellen. Taustatilanteessakin, ennen työvaiheita, keskimääräinen hengittyvän pölyn pitoisuus oli lähellä haitalliseksi tunnettua pitoisuutta. Myös ilman mikrobipitoisuudet olivat hyvin korkeita. Erityisen voimakasta pölyäminen oli eri työvaiheiden aikana. Toisaalta tutkittujen työvaiheiden kesto harvoin ylittää tuntia, ja ne toistuvat keskimäärin vain kymmenkunta kertaa vuodessa.

Turpeen pölyäminen johtui pitkälti turpeen alhaisesta kosteudesta. Tiloille toimitettujen turveerien kosteuspitoisuudet vaihtelivat $31-48 \%$ :n välillä. Ruotsalaisten laboratorio-oloissa tekemien kokeiden perusteella turpeen kosteuden pitäisi olla noin $50 \%$, jotta ilman pölypitoisuudet pysyisivät riittävän alhaisina. Tässä tutkimuksessa tilatasolla taustanäytteiden keskimääräinen pölypitoisuus ja tilalle toimitettujen eri turve-erien keskimääräinen kosteus korreloivat melko hyvin. Mitä kosteampaa turvetta tilalle oli toimitettu, sitä vähemmän ilmassa oli hengittyvää pölyä koko seurantajakson ajalla tarkasteltuna.

Toimivalla turvepohjalla ammoniakkipitoisuudet olivat selvästi lietelantasikaloissa ja purupohjasikaloissa mitattuja pienempiä. Turve sitoi ammoniakkia oletusten mukaisesti erittäin hyvin, mikäli pohja ei päässyt kostumaan liikaa. Kuormituksen noustua liiaksi pohjan toiminta hiipui ja ammoniakkipitoisuudet nousivat selvästi.

Tutkimuksen perusteella voidaan todeta, että ilman korkeat pöly- ja mikrobipitoisuudet edellyttävät hiukkassuodattimella varustetun hengityksensuojaimen käyttöä turvepohjaisessa kompostisikalassa työskenneltäessä. Erityisesti tulee suojautua voimakkaasti pölyävien työvaiheiden kuten sikojen siirtelyn, pohjan käännön tai vaihdon aikana. Hengityksensuojaimen hiukkassuodatusluokan tulee olla vähintään P2.

Turpeen pölyämistä kompostisikaloissa tulee vähentää. Tähän voidaan päästä käyttämällä riittävän kosteaa ja karkeaa turvetta. Lisäksi sumuttamalla vettä tai veden ja ruokaöljyn seosta voitaneen sikalan ilman pölypitoisuutta alentaa.

\section{Kirjallisuus}

Crook, B., Robertson, J., Travers Glass, S., Botheroyd, E., Lacey, J. \& Topping, M. 1991. Airborne dust, ammonia, micro-organisms, and antigens in pig confinement houses and the respiratory health of exposed farm workers. American Industrial Hygiene Association Journal 52:271-279.

Donham, K., Haglind, P., Pererson, Y., Rylander, R. \& Belin, L.1989. Environmental and health studies of farm workers in Swedish swine confinement buildings. British Journal of Industrial Medicine 46:31-37.

Kangas, J., Louhelainen, K. \& Husman, K. 1987. Gaseous health hazards in livestock confinement buildings. Journal of Agricultural Science in Finland. 57:57-62.

Louhelainen, K., Kangas, J., Seuri, M., Veijanen, A., Reiman, M., Pyykkönen, M., Rautiala, S. \& Viilos, P. 1998. Terveydelle haitalliset päästöt purupohjasikaloissa. Loppuraportti Maatalousyrittäjien eläkelaitokselle. 23 p.

Manninen, A., Kangas, J., Linnainmaa, M. \& Savolainen, H. 1989. Ammonia in Finnish poultry houses: effects of litter on ammonia levels and their reduction by technical binding agents. American Industrial Hygiene Association Journal 50:210-215.

Mäittälä, J., Heinonen-Tanski, H., Herve, S., Kangas, J., Louhelainen, K., Nikkola, T., Paasonen, M., Puumala, M., Rautiala, S., Seuri, M. \& Veijanen, A. 2001. Turve kestokuivikkeena sikaloissa. MTT:n julkaisuja. Sarja A 97. Jokioinen: MTT. 64 p. ISSN 1239-0854. 